Int. J. Morphol.,

36(3):984-990, 2018.

\title{
Metformin Protects Against Thioacetamide Induced Liver injury in Rats
}

\author{
La Metformina Protege Contra la Lesión Hepática Inducida por Tioacetamida en Ratas
}

Fahaid Al-Hashem ${ }^{1}$; Suliman AlHumayed ${ }^{2}$; Mohamed Abd Ellatif ${ }^{3}$; Shaimaa Nasr Amin ${ }^{4}$; Samaa Samir Kamar'; Bahjat Al-Ani ${ }^{\text {** }}$ \& Mohamed A Haidara ${ }^{1,4 *}$

AL-HASHEM, F.; ALHUMAYED, S.; ELLATIFF, M. A.; AMIN, S. N.; KAMAR, S. S.; AL-ANI, B. \& HAIDARA, M. A. Metformin protects against thioacetamide-induced liver injury in rats. Int. J. Morphol., 36(3):984-990, 2018.

SUMMARY: Potent heptatotoxic chemicals such as carbon tetrachloride and thioacetamide (TAA) are used to evaluate hepatoprotective agents. Here we sought to investigate the potential protective effect of the antidiabetic and antioxidant drug, metformin against liver injury induced by TAA. Model group rats received several injections of TAA ( $200 \mathrm{mg} / \mathrm{kg})$ before being sacrificed after 10 weeks and the protective group started the treatment two weeks prior to TAA injections and continued receiving both agents, metformin and TAA until the end of the experiment, week 10. Harvested liver tissues were examined using light microscopy and liver homogenates were assayed for oxidative and anti-oxidative stress markers that are known to be modulated in liver injury. Profound damage in the hepatic tissue of the model group such as liver fibrosis and destruction of hepatic architectures were revealed, which were protected by metformin comparable to the control group. TAA augmented the oxidative stress biomarker, malondialdehyde (MDA) and ameliorated the antioxidant superoxide dismutase (SOD), which were significantly $(\mathrm{p}<0.05)$ protected by metformin treatment. These results indicate that metformin effectively protects against TAA-induced hepatotoxicity in a rat model.

KEY WORDS: Liver fibrosis; Thioacetamide; Oxidative stress; Metformin; Rat model.

\section{INTRODUCTION}

The adverse effects of certain chemicals used in industries such as carbon tetrachloride and thioacetamide (TAA) on the human body are well documented (Mochizuki et al., 2009). TAA as a source of hydrogen sulfide to precipitate metal sulfides is a severe hepatotoxic agent that causes liver fibrosis (Kadir et al., 2011), cirrhosis and liver cancer (De Minicis et al., 2013), which depends on the length of exposure of the body to this agent. For example, a single injection of TAA caused acute liver injury in rats in the form of tissue necrosis and severe leukocytes infiltration between 6- $60 \mathrm{~h}$ following TAA injections; whereas, biomarkers of tissue necrosis, iNOS and NF-kB assessed in liver tissue peaked at one h post TAA injection (Chen et al., 2008). Inflammation and necrosis of liver tissue also observed after one week following a single injection of TAA (Luo et al.,
2015). On the other hand, chronic liver injury model induced by TAA injection twice a week for 6 to 10 weeks caused liver fibrosis and cirrhosis (Wallace et al., 2015).

Chronic liver disease represents a major challenge to the health sector since it can lead to liver failure as well as the high cost of liver transplantation (Neff et al., 2011). Liver fibrosis represents the common response of the liver to a variety of insults, including hepatitis, toxins, viruses, alcohol abuse, metabolic diseases, autoimmune diseases, and cholestatic liver disease (Friedman, 2003). Regression of hepatic fibrosis could be a potential therapeutic choice to prevent the progression to liver cirrhosis and failure (Liedtke et al., 2013; Czaja, 2014). Oxidative stress is known to be involved in the pathology of metabolic liver disease and in

\footnotetext{
${ }^{1}$ Departments of Physiology, College of Medicine, King Khalid University, Abha 61421, Saudi Arabia.

${ }^{2}$ Departments of Medicine, College of Medicine, King Khalid University, Abha 61421, Saudi Arabia.

${ }^{3}$ Departments of Biochemistry, College of Medicine, King Khalid University, Abha 61421, Saudi Arabia.

${ }^{4}$ Departments of Physiology, Kasr Al-Aini Faculty of Medicine, Cairo University, Cairo, Egypt.

${ }^{5}$ Departments of Medical Histology, Kasr Al-Aini Faculty of Medicine, Cairo University, Cairo, Egypt.

SOURCE OF FUNDING. This work was supported by the Research Deanship of King Khalid University, Abha, Saudi Arabia; Grant number KKUProject No. 284.

*Equally contributed.
} 
TAA induced chronic liver injuries (Li et al., 2015). Imbalance between pro-oxidant and antioxidant defence may affect the extent of liver oxidative damage. Administration of antioxidants in cases of chronic liver diseases and fibrosis may ameliorate or prevent this condition (Casas-Grajales \& Muriel, 2015).

The anti-hyperglycaemic and antioxidant drug, metformin (Cicero et al., 2012; Chukwunonso Obi et al., 2016) that is widely used to treat type 2 diabetes mellitus was shown to ameliorate several types of liver diseases such as nonalcoholic fatty liver disease (NAFLD), improving liver injury in type 2 diabetes with hyperlipidaemia (Matafome $e t$ al., 2011). In addition, metformin has been shown to protect primary rat hepatocytes against oxidative stress-induced apoptosis (Conde de la Rosa et al., 2015). Here we investigated the potential protective effects of metformin on TAA-induced liver injury using basic histological staining and biochemical methods. We compared the status of liver tissue sections obtained from the model and metformin treated groups, and also monitored the levels of oxidative stress biomarkers in liver tissue homogenates from these animals.

\section{MATERIAL AND METHOD}

Animals. Albino male rats weighing 180-200 g were used for the experiments with the approval of Ethical Committee of the college of medicine, King Khalid University, Abha, Saudi Arabia. The animals were obtained from the animal house of the College of Medicine of King Khalid University where they fed with standard rat's pellets and allowed free access to water. They were housed at a controlled ambient temperature of $25 \pm 2{ }^{\circ} \mathrm{C}$ and $50 \pm 10 \%$ relative humidity, with 12-h light/12-h dark cycles. Experiments were performed according to the Guide for the Care and Use of Laboratory Animals published by the US National Institutes of Health (NIH publication No. 85-23, revised 1996).

Experimental design. After a one week adaptation period, rats were randomly allocated into 4 groups $(n=6)$ as follows: Control group (Control): non- treated rats that were injected intraperitoneally (i.p.) with vehicle; metformin group (Met): rats treated with metformin $(200 \mathrm{mg} / \mathrm{kg})$ daily for 10 weeks; TAA-treated group, the model group (TAA): rats were injected i.p. with $200 \mathrm{mg} / \mathrm{kg}$ TAA, 2 x per week for 8 weeks (week 3 -week 10); the protective group (Met+TAA): rats were treated with metformin from week 1 - week 10 and injected with TAA from week 3 - week 10.

Histological Analysis. Liver specimens were immediately fixed in $10 \%$ formal saline for $24 \mathrm{~h}$. Paraffin blocks were prepared and $5 \mathrm{~mm}$ thick sections were subjected to Masson's trichrome that stains collagen in blue, which determine hepatic fibrosis. Liver sections were also stained with hematoxylin and eosin (H\&E) stain to elucidate the status of hepatic architecture and the structural changes. Morphometry and statistical analysis of the degree of tissue fibrosis were performed using "Leica Qwin $500 \mathrm{C}$ " image analyzer (Cambridge, UK). Areas \% of collagen deposition were determined in 10 non overlapping low power fields for each group. Elements of the liver capsule were excluded from the computations. Quantitative data were summarized as means and standard deviations (SD) and compared using analysis of variance (ANOVA) followed by post-Hoc analysis (Tukey test). P-values $<0.05$ were considered statistically significant. Calculations were made on statistical package of social science (SPSS) software, version 19.

Measurements of SOD and MDA. SOD and MDA (measured as TBARS) levels were measured in liver homogenates using superoxide dismutase assay kit (SOD), rat, Cayman Chemical, Cat. No. 706002 and Thiobarbituric Acid Reactive Substances, TBARS Assay kit, Cayman Chemical Item Number 10009055 as recommended by the manufacturer. Tissue homogenates were prepared by taking parts of the livers obtained from the rats of all groups, freshly washed with phosphate buffered saline (PBS), pH 7.4. Then, they were homogenized with an ultrasonic homogenizer in cold phosphate buffer, $\mathrm{pH}$ 7.4, containing ethylene-diaminetetra-acetic acid (EDTA). The supernatant obtained from each sample was used for SOD and MDA analysis.

Statistical analysis. The data was expressed as mean \pm standard deviation (SD). Data was processed and analyzed using the SPSS version 10.0 (SPSS, Inc., Chicago, Ill., USA). Oneway ANOVA was done followed by Tukey's post hoc test. Pearson correlation statistical analysis was done for detection of a probable significance between two different parameters. Results were considered significant if $\mathrm{p} \leq 0.05$.

\section{RESULTS}

Induction of liver fibrosis in rats by TAA. All animals that were injected intraperitoneally with TAA $(100 \mathrm{mg} / \mathrm{kg}$ body weight) twice a week for 8 weeks developed liver fibrosis (Fig. 1). Tissue preparations for light microscopy analysis from the liver lobes of the model group stained with Masson's trichrome revealed a substantial collagen deposition (arrows) around portal tract (Figs. 1B and 1C) compared to a fine collagen deposition (arrow) in liver sections obtained from the control group (Figs. 1A and 1C). 

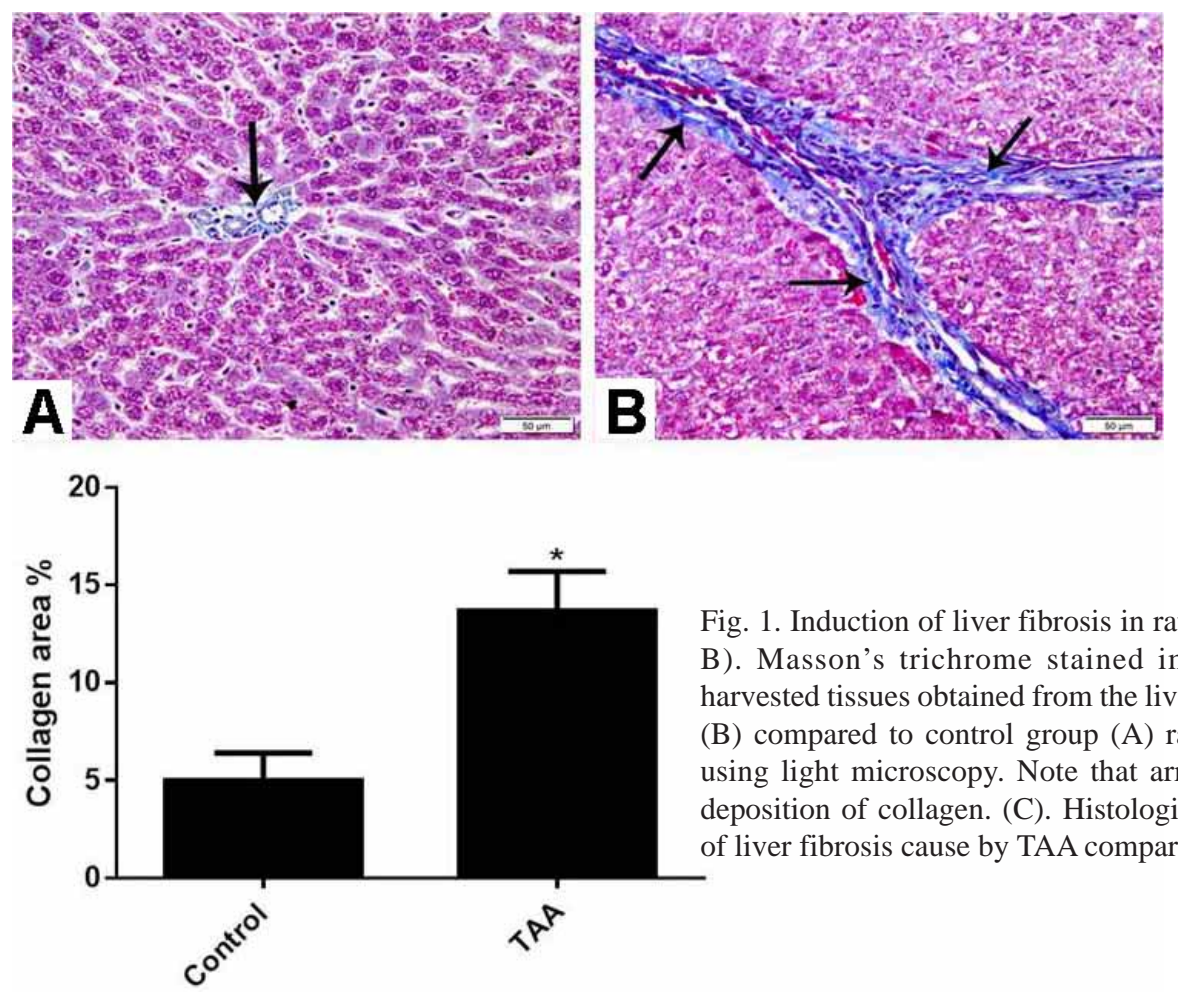

Fig. 1. Induction of liver fibrosis in rats by TAA.(A and B). Masson's trichrome stained images (x200) of harvested tissues obtained from the liver of model group (B) compared to control group (A) rats are visualized using light microscopy. Note that arrows point to the deposition of collagen. (C). Histological quantification of liver fibrosis cause by TAA compared to control.

Metformin inhibits TAA-induced modulation of oxidative and anti-oxidative stress biomarkers. To investigate whether metformin can modulate cellular oxidative stress known to be up-regulated in liver injury (Le Lay et al., 2014), we used Thiobarbituric Acid Reactive Substances (TBARS) assay kit that measures the reactive species, MDA generated from lipid peroxidation. In addition, we monitored the levels of the antioxidative enzyme, SOD. Liver homogenates MDA levels increased by around five-fold in the model group that was significantly $(\mathrm{p}<0.05)$ inhibited by metformin (Fig. 2A). TAA caused a four-fold reduction in the antioxidative enzyme, superoxide dismutase (SOD), which was significantly $(\mathrm{p}<0.05)$ augmented by metformin (Fig. $2 \mathrm{~B})$. However, the levels of MDA and SOD in the Met + TAA group were still significant $(\mathrm{p}<0.05)$ to the control group (Figs. 2A and 2B).
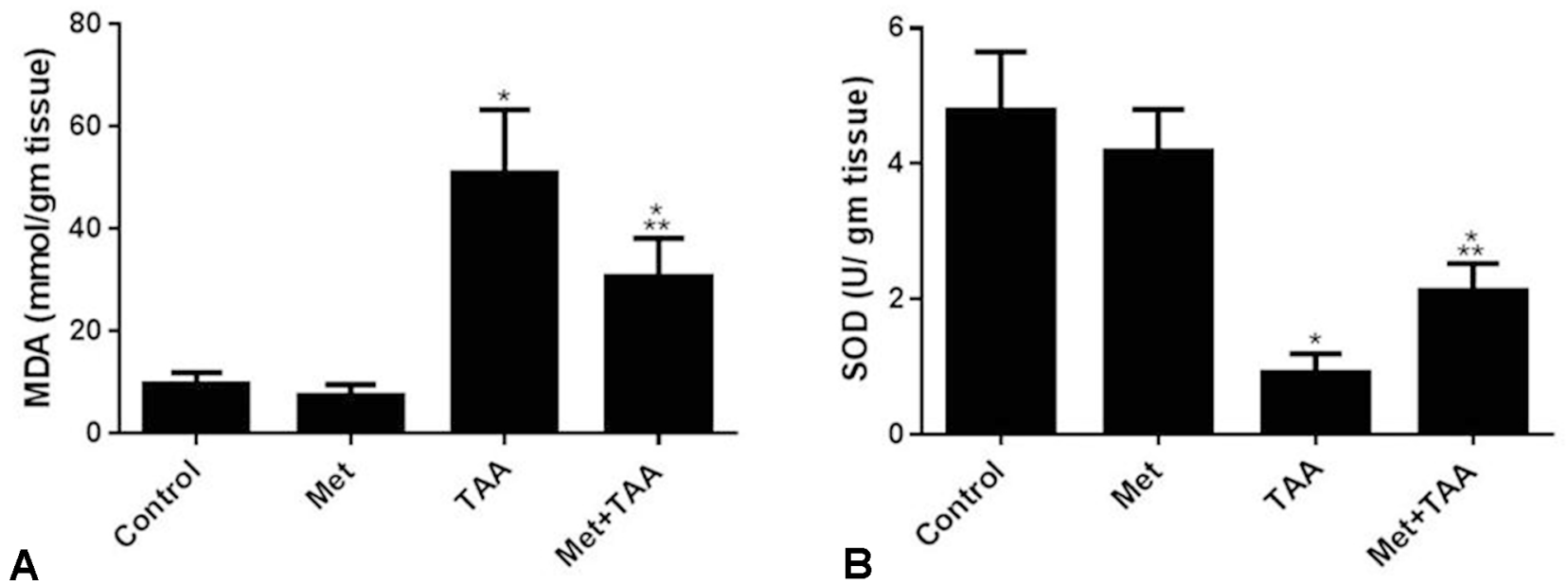

Fig. 2. Metformin inhibits TAA-caused an induction of oxidative stress and suppression of anti-oxidative stress. Liver tissue levels of MDA (A) and SOD (B) were measured 10 weeks after the start of metformin pre-treatment protocol and 8 weeks after the start of TAA injections in rats. Results represent the mean $( \pm \mathrm{SD}) ; \mathrm{n}=6$ for each group. Experiments were performed in triplicate. All shown $\mathrm{p}$ values are significant. $* \mathrm{p}<0.05$ versus control, $* * \mathrm{p}<0.05$ versus TAA. 
Metformin protects hepatic tissue against fibrosis and other injuries induced by TAA. To test the hypothesis that metformin can protect liver organ against fibrosis and other injuries induced by TAA, we pre-treated a group of rats (Met + TAA) with metformin $(200 \mathrm{mg} / \mathrm{kg})$ daily starting two weeks before the hepatotoxic agent, TAA was given to these animals, and continued giving the drug until the end of the experiment on week 10, whereas, TAA was injected twice a week from week 3 till week 10. Liver tissues were examined by light microscopy after staining with Masson's trichrome and H\&E to quantify the degree of liver fibrosis and to examine the structural changes. Masson's trichrome stained liver sections revealed that TAA substantially induced liver fibrosis that was significantly $(\mathrm{p}<0.05)$ prevented by metformin to levels comparable to the control group as determined by image analyzer that measured the mean area percent of collagen deposition (Figs. 3A-3D).

Furthermore, H\&E images revealed a normal liver histology in the control group (Fig. 4A and 4B); showing cords of hepatocytes displaying an acidophilic cytoplasm and vesicular nuclei radiating from the central veins (CV), and surrounding the portal tract (PT).Whereas, the TAA group (Figs. 4C and 4D) demonstrated multiple hepatocytes with vacuolated cytoplasms and a dark pyknotic nuclei (bifid arrow), dilated sinusoids (S), dilated and congested blood vessels (D) and inflammatory cells infiltrating the portal area (arrow). The protective group, Met+TAA (Figs. 4E and 4F) exhibited restored normal parenchymatous architecture of the liver, although little cellular infiltration (arrow) and vascular congestion were noted (arrow head).
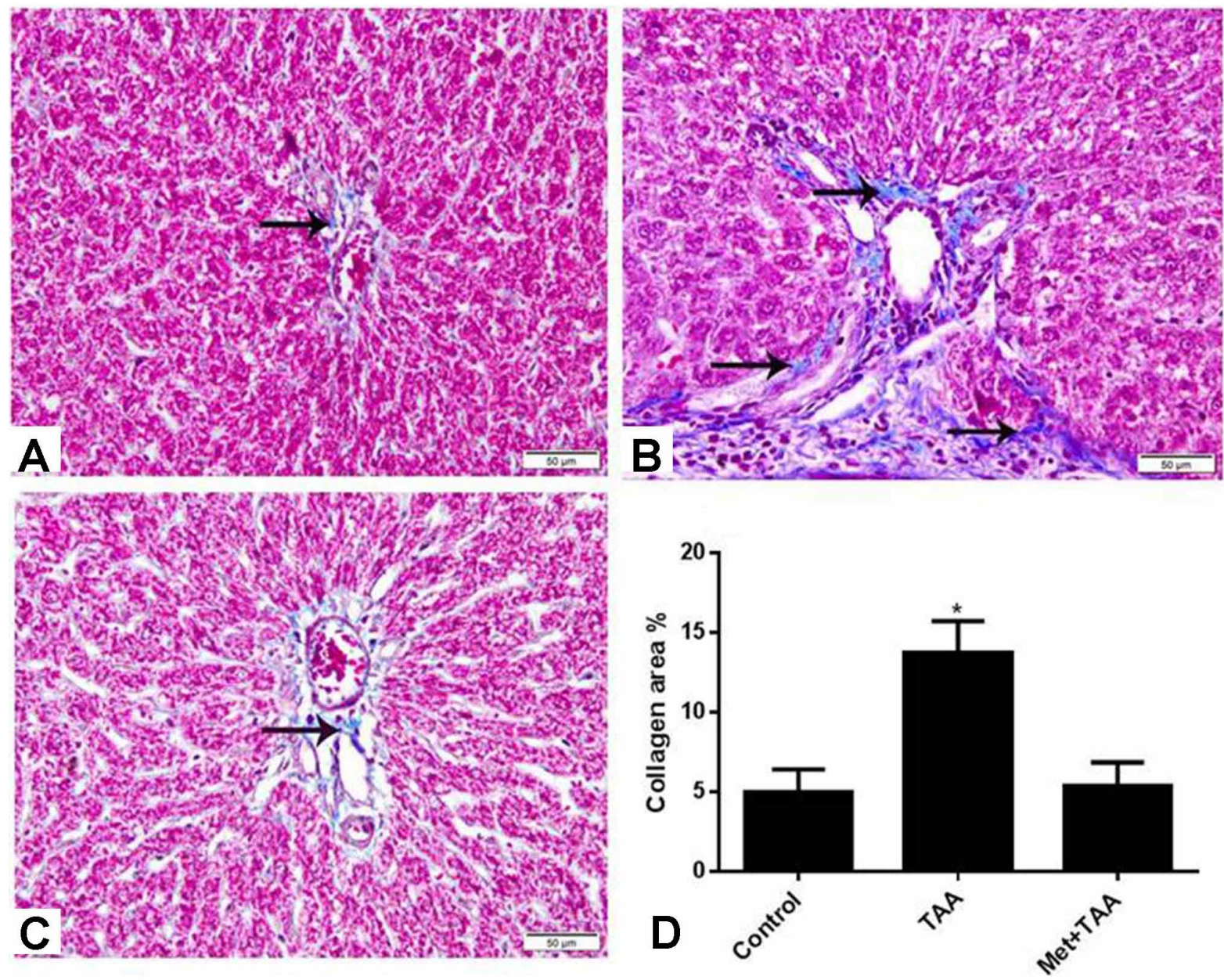

Fig. 3. Metformin protects against TAA-induced liver fibrosis. (A - C). Masson's trichrome stained images (x200) of harvested tissues obtained from the liver of the control group (A),TAA injected group (B), and the protective group, Met + TAA (C) rats are visualized by light microscopy. Note that arrows point to the deposition of collagen. (D). Histological quantification of collagen as indicator of liver fibrosis in the three groups mentioned above. 

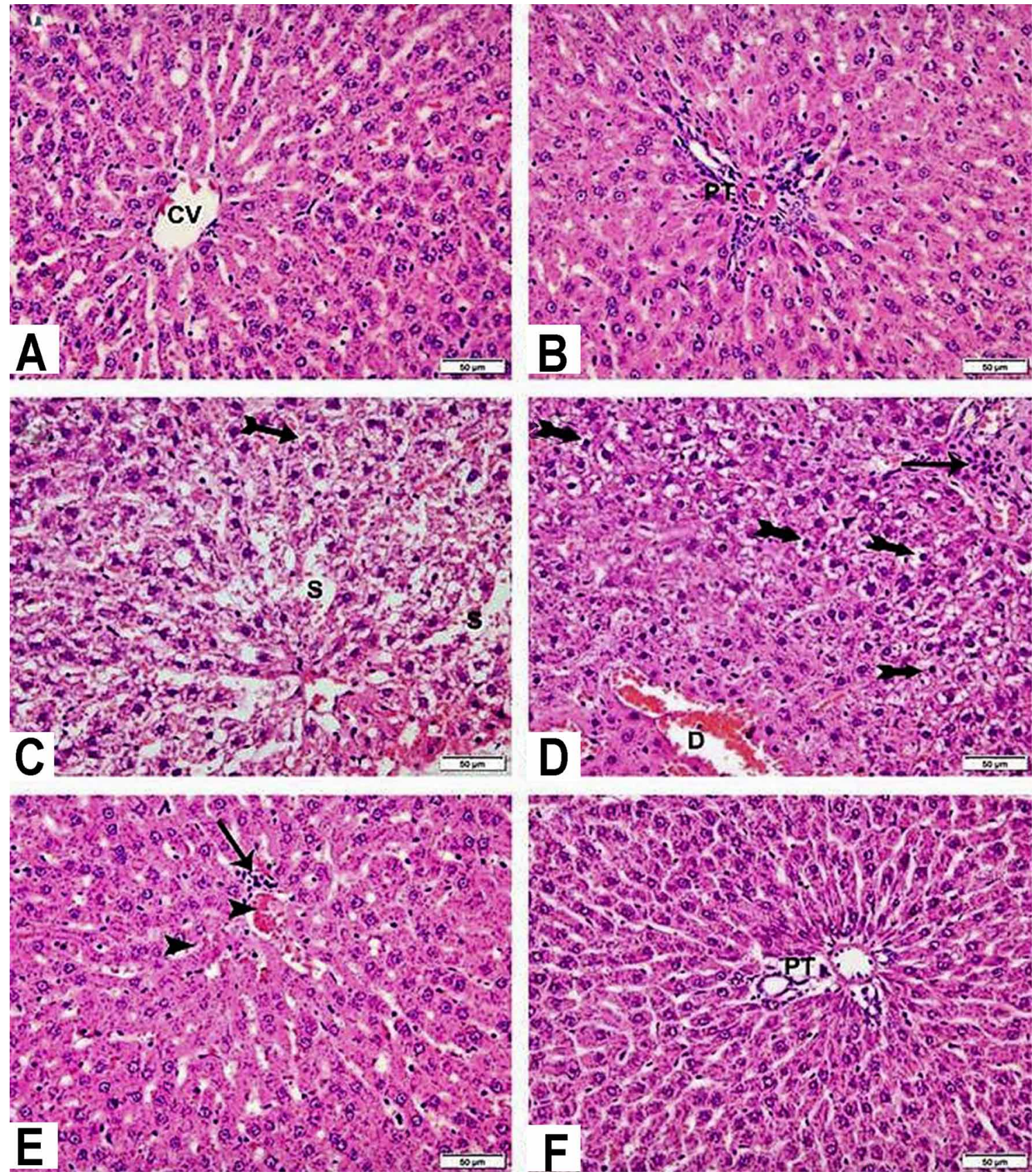

Fig. 4. Metformin protects against TAA-induced liver injuries. (A - F). H\&E stained images (x200) of harvested tissues obtained after 10 weeks from the liver in different groups of rats used in the study; Control group (A and B), TAA, model group (C and D), and Met+TAA, protective group (E and F). Note that bifid arrows shown in C and D point to hepatocytes with vacuolated cytoplasms and a dark pyknotic nuclei; arrows in D and E point to inflammatory cells; and arrow head in E point to vascular congestion. Abbreviations: CV, central vein; PT, portal tract; S, dilated sinusoid; D, dilated and congested blood vessels.

\section{DISCUSSION}

The main objective of our study was to investigate whether the antidiabetic drug metformin can protect the liver from the hepatotoxic agent TAA in a chronic liver injury animal model. Therefore, we induced liver injury in rats using 
TAA in the presence and absence of metformin. The principal findings in our study were that metformin protected liver lobes against liver fibrosis and necrosis induced by TAA (Figs. 3 and 4), and inhibited biomarkers of oxidative stress (Fig. 2) and liver injury enzymes (data not shown) in liver tissue homogenates and blood. The above conclusions are supported by the ELISA (Fig. 2) and light microscopy (Figs. 1,3 , and 4) data indicating that TAA induced liver fibrosis, necrosis, and lipid peroxidation product (MDA) in rats, which were substantially protected by the use metformin (Figs. 2-4). In addition, metformin augmented the antioxidant enzyme SOD (Fig. 2B).

Elevated levels of liver injury biomarkers are documented in many liver diseases such as obese patients with fatty livers and in TAA-induced liver fibrosis in rats (Al Akwaa et al., 2011; Czechowska et al., 2015). Furthermore, oxidative stress is also known to be involved in the pathology of liver disease including TAA-induced acute hepatic encephalopathy (Mustafa et al., 2013) and TAA-induced liver fibrosis (Kwak et al., 2011). These reports are in agreement with our findings shown in Figure 2, and the significant reduction in the levels of MDA, and the upregulation of SOD upon treatment with metformin may account for the observed improvement of the liver histology as indicated by inhibition of fibrosis (Fig. 3), fewer inflammatory cells, and a preserved architecture of liver tissue (Fig. 4).

Metformin was previously used to treat liver injury induced by endotoxin in rats after partial hepatectomy ( $\mathrm{La}$ Mura et al., 2013) and also treated NAFLD (Yabiku et al., 2017). These reports are in agreement with our results that showed effective protection of hepatocytes with metformin (Figs. 3 and 4). However, a recent meta-analysis clinical trials of pharmacological agents in patients with the advanced type of NAFLD, non-alcoholic steatohepatitis (NASH) reported that liver fibrosis does not improve with metformin (Said \& Akhter, 2017). The discrepancies could be attributed to the type of liver disease, the assessment methods used, and the different species involved in these studies.

In summary, our data demonstrate that TAA induced liver fibrosis and necrosis, and the induction of oxidative stress biomarkers, which were protected by metformin.

\section{ACKNOWLEDGEMENTS}

The author would like to thank Dr. Mariam Al-Ani from Dental Care Partnership, Sutton Coldfield, Birmingham, UK for proofreading the manuscript.
AL-HASHEM, F.; ALHUMAYED, S.; ELlATIFF, M. A.; AMIN, S. N.; KAMAR, S. S.; AL-ANI, B. \& HAIDARA, M. A. La metformina protege contra la lesión hepática inducida por tioacetamida en ratas. Int. J. Morphol., 36(3):984-990, 2018.

RESUMEN: Para evaluar los agentes hepatoprotectores se usan químicos heptatotóxicos potentes como el tetracloruro de carbono y la tioacetamida (TAA). En este estudio tratamos de investigar el efecto protector potencial de la droga antidiabética y antioxidante, la metformina contra la lesión hepática inducida por TAA. Las ratas del grupo modelo recibieron varias inyecciones de TAA (200 mg/kg) durante 10 semanas antes de ser sacrificadas, y el grupo protector comenzó el tratamiento dos semanas antes de las inyecciones TAA y continuó recibiendo ambos agentes, metformina y TAA, hasta el final del experimento. Los tejidos hepáticos se examinaron usando microscopía óptica y se analizaron los homogeneizados hepáticos en busca de marcadores de estrés oxidativo y antioxidante los que están modulados en la lesión hepática. Se observaron daños significativos en el tejido hepático del grupo modelo como la fibrosis hepática y destrucción de la arquitectura hepática, que estaban protegidas por la metformina comparable al grupo control. TAA aumentó el biomarcador de estrés oxidativo, malondialdehído (MDA) y mejoró la enzima antioxidante superóxido dismutasa (SOD), que fueron protegidas significativamente $(\mathrm{p}<0,05)$ por el tratamiento con metformina. Estos resultados indican que la metformina protege eficazmente contra la hepatotoxicidad inducida por TAA en un modelo de rata.

PALABRAS CLAVE: Fibrosis hepática; Tiocetamida; Estrés oxidativo; Metformina; Modelo de rata.

\section{REFERENCES}

Al Akwaa, A.; El Zubier, A. \& Al Shehri, M. Pattern of liver function tests in morbidly obese Saudi patients undergoing bariatric surgery. Saudi J. Gastroenterol., 17(4):252-5, 2011.

Casas-Grajales, S. \& Muriel, P. Antioxidants in liver health. World J. Gastrointest. Pharmacol. Ther, 6(3):59-72, 2015.

Chen, T. M.; Subeq, Y. M.; Lee, R. P.; Chiou, T. W. \& Hsu, B. G. Single dose intravenous thioacetamide administration as a model of acute liver damage in rats. Int. J. Exp. Pathol., 89(4):223-31, 2008.

Chukwunonso Obi, B.; Chinwuba Okoye, T.; Okpashi, V. E.; Nonye Igwe, C. \& Olisah Alumanah, E. Comparative study of the antioxidant effects of metformin, glibenclamide, and repaglinide in alloxan-induced diabetic rats. J. Diabetes Res., 2016:1635361, 2016.

Cicero, A. F.; Tartagni, E. \& Ertek, S. Metformin and its clinical use: new insights for an old drug in clinical practice. Arch. Med. Sci., 8(5):90717, 2012.

Conde de la Rosa, L.; Vrenken, T. E.; Buist-Homan, M.; Faber, K. N. \& Moshage, H. Metformin protects primary rat hepatocytes against oxidative stress-induced apoptosis. Pharmacol. Res. Perspect., 3(2):e00125, 2015.

Czaja, A. J. Hepatic inflammation and progressive liver fibrosis in chronic liver disease. World J. Gastroenterol., 20(10):2515-32, 2014.

Czechowska, G.; Celinski, K.; Korolczuk, A.; Wojcicka, G.; Dudka, J.; Bojarska, A. \& Reiter, R. J. Protective effects of melatonin against thioacetamide-induced liver fibrosis in rats. J. Physiol. Pharmacol., 66(4):567-79, 2015. 
De Minicis, S.; Kisseleva, T.; Francis, H.; Baroni, G. S.; Benedetti, A.; Brenner, D.; Alvaro, D.; Alpini, G. \& Marzioni, M. Liver carcinogenesis: rodent models of hepatocarcinoma and cholangiocarcinoma. Dig. Liver Dis., 45(6):450-9, 2013.

Friedman, S. L. Liver fibrosis -- from bench to bedside. J. Hepatol., 38 Suppl. 1:S38-53, 2003

Kadir, F. A.; Othman, F.; Abdulla, M. A.; Hussan, F. \& Hassandarvish, P. Effect of Tinospora crispa on thioacetamide-induced liver cirrhosis in rats. Indian J. Pharmacol., 43(1):64-8, 2011.

Kwak, K. G.; Wang, J. H.; Shin, J. W.; Lee, D. S. \& Son, C. G. A traditional formula, Chunggan extract, attenuates thioacetamide-induced hepatofibrosis via GSH system in rats. Hum. Exp. Toxicol., 30(9):132232, 2011.

La Mura, V.; Pasarín, M.; Meireles, C. Z.; Miquel, R.; Rodríguez-Vilarrupla, A.; Hide, D.; Gracia-Sancho, J.; García-Pagán, J. C.; Bosch, J. \& Abraldes, J. G. Effects of simvastatin administration on rodents with lipopolysaccharide-induced liver microvascular dysfunction. Hepatology, 57(3):1172-81, 2013.

Le Lay, S.; Simard, G.; Martinez, M. C. \& Andriantsitohaina, R. Oxidative stress and metabolic pathologies: From an adipocentric point of view. Oxid. Med. Cell. Longev., 2014:908539, 2014.

Li, S.; Tan, H. Y.; Wang, N.; Zhang, Z. J.; Lao, L.; Wong, C. W. \& Feng, Y. The role of oxidative stress and antioxidants in liver diseases. Int. J. Mol. Sci., 16(11):26087-124, 2015.

Liedtke, C.; Luedde, T.; Sauerbruch, T.; Scholten, D.; Streetz, K.; Tacke, F.; Tolba, R.; Trautwein, C.; Trebicka, J. \& Weiskirchen, R. Experimental liver fibrosis research: update on animal models, legal issues and translational aspects. Fibrogenesis Tissue Repair, 6(1):19, 2013.

Luo, M.; Dong, L.; Li, J.; Wang, Y. \& Shang, B. Protective effects of pentoxifylline on acute liver injury induced by thioacetamide in rats. Int. J. Clin. Exp. Pathol., 8(8):8990-6, 2015.

Matafome, P.; Louro, T.; Rodrigues, L.; Crisóstomo, J.; Nunes, E.; Amaral, C.; Monteiro, P.; Cipriano, A. \& Seiça, R. Metformin and atorvastatin combination further protect the liver in type 2 diabetes with hyperlipidaemia. Diabetes Metab. Res. Rev., 27(1):54-62, 2011.

Mochizuki, M.; Shimizu, S.; Urasoko, Y.; Umeshita, K.; Kamata, T.; Kitazawa, T.; Nakamura, D.; Nishihata, Y.; Ohishi, T. \& Edamoto, H. Carbon tetrachloride-induced hepatotoxicity in pregnant and lactating rats. J. Toxicol. Sci., 34(2):175-81, 2009.

Mustafa, H. N.; El Awdan, S. A. \& Hegazy, G. A. Protective role of antioxidants on thioacetamide-induced acute hepatic encephalopathy: biochemical and ultrastructural study. Tissue Cell, 45(5):350-62, 2013.

Neff, G. W.; Duncan, C. W. \& Schiff, E. R. The current economic burden of cirrhosis. Gastroenterol. Hepatol. (N. Y.), 7(10):661-71, 2011.

Said, A. \& Akhter, A. Meta-Analysis of Randomized Controlled Trials of Pharmacologic Agents in Non-alcoholic Steatohepatitis. Ann. Hepatol., 16(4):538-47, 2017.

Wallace, M. C.; Hamesch, K.; Lunova, M.; Kim, Y.; Weiskirchen, R.; Strnad, P. \& Friedman, S. L. Standard operating procedures in experimental liver research: thioacetamide model in mice and rats. Lab. Anim., 49(1 Suppl.):21-9, 2015.

Yabiku, K.; Mutoh, A.; Miyagi, K. \& Takasu, N. Effects of oral antidiabetic drugs on changes in the liver-to-spleen ratio on computed tomography and inflammatory biomarkers in patients with type 2 diabetes and nonalcoholic fatty liver disease. Clin. Ther, 39(3):558-566, 2017.

\author{
Corresponding author: \\ Professor Mohamed A Haidara \\ Department of Physiology \\ College of Medicine \\ King Khalid University \\ Abha 61421 \\ SAUDI ARABIA
}

E-mail: haidaram@hotmail.com

Received: $20-12-2017$

Accepted: 22-02-2018 